\title{
Formulation Study of Chitosan Microparticles Loaded with Lactoferrin
}

\author{
Hiraku Onishi*, Yoshiharu Machida, Ryuya Yoshida and Ken-ichi Watanabe
}

Department of Drug Deliver Research, Hoshi University, Japan

\begin{abstract}
Lactoferrin (LF) is known to show various useful biological features such as antimicrobial, antiviral, antitumor and anti-inflammatory effects. However, orally administered LF undergoes enzymatic degradation in the gastrointestinal tract, resulting in extensive decrease of such functions. The purpose of this study is to develop a useful oral delivery system of LF. Also, chitosan (Ch) was adopted as a carrier because it is yielded abundantly and a safe polymer. LF-loaded Ch microparticles were produced by the emulsification-evaporation technique using sorbitan sesquioleate (SO-15) and sorbitan trioleate (SO-30) as surfactants. The resultant LF-loaded Ch microparticles were evaluated from the viewpoints of particle size, shape, drug content and in vitro release in the gastric and intestinal pHs. The selected LF-loaded microparticles (MS4) were coated with an enteric coating polymer, Eudragit L100 (EL-100). The resultant microparticles (E/MS4) were protected from the deformation in the gastric $\mathrm{pH}$, and exhibited fairly appropriate release profiles of LF. Thus, enteric-coated MS4 was suggested to be possibly useful as an orally-taken delivery system of LF.
\end{abstract}

Keywords: Lactoferrin; Chitosan; Microparticle; Enteric coating; Oral delivery system

\section{Introduction}

Lactoferrin (LF) was found as a multifunctional iron-binding glycoprotein, and is widely contained in milk, saliva, tears, various exocrine secretions and neutrophil granules [1,2]. It exhibits antimicrobial [3,4], antiviral [5], antitumor [6], anti-inflammatory [7] and immunomodulation [8] activities. Recently, since it is a natural substance and very safe, such biological functions are to be of great interest in the medical fields. LF functions in various manners. It works against microbes and viruses not only by direct binding [9-14] but also by interaction with host cells [15] or activation of immune systems $[16,17]$. Recently, LF is used as a supplement in various countries.

Since LF is a glycoprotein, it is subjected to enzymatic degradation $[18,19]$. LF, injected intravenously, was eliminated rapidly from the blood circulation [20]. Therefore, it is usually taken orally at a fairly large dose because the oral dosing is conducted easily and safely. In addition, the LF receptor in the intestinal membrane is importantly related to the activation of gut-associated lymphoid tissue (GALT) $[21,22]$. Therefore, the delivery of intact LF to the intestinal part is essential to the sufficient expression of LF functions [23-25]. As LF is subjected to peptic degradation, its considerable amount is degraded before LF reaches the receptor [24,26]. The protection of LF from the gastric conditions has been reported to be important in the oral dosing of $\operatorname{LF}[24,25,27]$.

Chitosan $(\mathrm{Ch})$ is a biopolymer produced by deacetylation of chitin, abundantly yielded from shells of crabs or shrimps and cell walls of fungi etc. [28]. As it is very safe in oral use, it is used as a food additive or supplement. As $\mathrm{Ch}$ is not water-soluble in neutral and basic $\mathrm{pH}$, it is expected as an excipient for medical or pharmaceutical products $[29,30]$. As $\mathrm{Ch}$ is soluble in acidic aqueous solution, its solution can be applied to make various products. In addition, $\mathrm{Ch}$ is less or insoluble at intestinal $\mathrm{pH}, \mathrm{Ch}$ is adequate to the delivery to oral mucosa or intestinal parts. We have tried to apply $\mathrm{Ch}$ as microparticulate delivery devices such as simple ones and complex-type ones [31-33]. In the previous paper, Ch microparticles loaded with LF were produced, and their possibilities toward topical application or oral use were evaluated in vitro, in which the simple formulation composed of Ch and LF was demonstrated to exhibit smaller size $(4.9 \mu \mathrm{m})$ and prolonged release over $24 \mathrm{~h}$. In the present study, Ch microparticles loaded with LF were newly produced in order to develop an oral delivery system to elevate intestinal or systemic immunity. A high LF content, sufficient LF release $[2,27]$ and the particle size of submicron to a few micrometer size $[34,35]$ will be better to achieve biological potential or intestinal localization and retention of LF. As to the present preparation, the effect of the LF/Ch ratio on the particle characteristics was examined in detail. Also, the influence of surfactant species (sorbitan sesquioleate or sorbitan trioleate) used in emulsification-evaporation process was investigated for the particle characteristics. The adequate $\mathrm{Ch}$ microparticles loaded with LF were selected from those preparations based on particle features such as particle size and LF content, and on in vitro release. Finally, the chosen $\mathrm{Ch}$ microparticles were enteric-coated with Eudragit L100 (EL-100) for oral dosing, and the utility of entericcoated MS4 were evaluated in vitro.

\section{Materials and Methods}

\section{Materials}

Bovine lactoferrin (LF) was donated by NRL Pharma Inc. (Kawasaki Japan). Chitosan (Ch, MW 100,000 - 200,000, deacetylation degree = $80 \%)$ and liquid paraffin were purchased from Wako Pure Chemical Industries, Ltd. (Osaka, Japan). Sorbitan sesquioleate (SO-15) was obtained from Nikko Chemicals Co., ltd. (Tokyo, Japan). Sorbitan Trioleate (SO-30) was purchased from Tokyo Chemical Industry Co., Ltd. (Tokyo, Japan). Eudragit L100 (EL-100) was supplied by was obtained from Rohm GmbH Chemische Fabrik (Darmstadt, Germany) and used as an enteric coating polymer. A Pierce BCA Protein Assay kit was purchased from Thermo Fisher Scientific Inc. (Rockford, IL,

*Corresponding author: Hiraku Onishi, Department of Drug Deliver Research, Hoshi University, 2-4-4, Ebara, Shinagawa-ku, Tokyo 142-850, Japan, Tel: 4105546516; Fax: 4105546517; E-mail: onishi@hoshi.ac.jp

Received January 30, 2015; Accepted March 27, 2015; Published April 03, 2015

Citation: Onishi H, Machida Y, Yoshida R, Watanabe K (2015) Formulation Study of Chitosan Microparticles Loaded with Lactoferrin. J Mol Genet Med 7: 100 doi:10.4172/1747-0862.1000166

Copyright: @ 2015 Onishi $\mathrm{H}$, et al. This is an open-access article distributed under the terms of the Creative Commons Attribution License, which permits unrestricted use, distribution, and reproduction in any medium, provided the original author and source are credited 
USA), and used for the determination of LF concentration. All other chemicals used were of reagent grade.

\section{Preparation of LF-loaded Ch microparticles}

LF-loaded $\mathrm{Ch}$ microparticles were prepared by the W/O emulsification-evaporation method. The formulations in the preparation were shown in Table $1 . \mathrm{LF}$ and $\mathrm{Ch}$, with their amounts shown in Table 1, were dissolved in $10 \mathrm{~mL}$ of $1 \%(\mathrm{v} / \mathrm{v})$ acetic acid aqueous solution. The mixed solution was added drop by drop at a fairly rapid speed to $150 \mathrm{~mL}$ of liquid paraffin containing $1 \%$ (v/v) surfactant. The resultant mixture was stirred at $1000 \mathrm{rpm}$ for $1.5 \mathrm{~h}$ and sonicated at $28 \mathrm{~Hz}(100 \mathrm{~W})$ for $10 \mathrm{~min}$. The resultant emulsion was evaporated with the reduced pressure at $40^{\circ} \mathrm{C}$ under stirring at $400 \mathrm{rpm}$ until it became to be white suspension. $\mathrm{n}$-Hexane was mixed to the suspension with the same volume, and the mixture was centrifuged at $3000 \times \mathrm{g}$ for $10 \mathrm{~min}$. The precipitate was taken by discarding the supernatant, and washed several times with $\mathrm{n}$-hexane, and dried in a desiccator.

\section{Measurement of particle characteristics}

LF-loaded Ch microparticles were investigated for particle size, shape, LF content and encapsulation efficiency. The microparticles were coated thinly (10 nm in thickness) with platinum using a JFC-1600 Auto Fine Coater made by JEOL (Tokyo, Japan), and observed using a JEOL JSM-5600LV scanning electron microscope, in which their photomicrographs were taken. The particle shape and surface structure were observed from each photo. The Green diameter was measured for 200 particles chosen at random based on the scale bar, and the mean size and deviation were calculated $(n=200)$.

The microparticles $(5 \mathrm{mg})$ were dissolved in $10 \mathrm{~mL}$ of $2 \%(\mathrm{v} / \mathrm{v})$ acetic acid aqueous solution. The obtained solution $(200 \mu \mathrm{L})$ was measured for the LF concentration using a BCA protein Assay kit, which was validated using LF standard samples dissolved in $2 \%(\mathrm{v} / \mathrm{v}) \mathrm{AcOH}$.

The LF content and encapsulation efficiency of the microparticles were calculated in the following equation.

Content $(\%)=100 \times[\mathrm{LF}$ amount in sample micropartcles $(\mathrm{mg})] /$ [amount of sample microparticles $(\mathrm{mg})$ ]

Encapsulation efficiency $(\%)=100 \times$ [amount of incorporated LF (mg)] / [amount of added LF (mg)]

\section{In vitro release from $\mathrm{LF}$-loaded $\mathrm{Ch}$ microparticles}

The 1st ( $\mathrm{pH}$ 1.2) and 2nd ( $\mathrm{pH}$ 6.8) fluids in Japanese Pharmacopoeia 16 were used as the artificial gastric and intestinal fluids. LF-loaded Ch microparticles $(5 \mathrm{mg}$ ) was added to $10 \mathrm{~mL}$ of the 1 st or 2 nd medium, and incubated at $37^{\circ} \mathrm{C}$ under the condition of horizontal shaking at $100 \mathrm{rpm}$. The upper solution $(200 \mu \mathrm{L})$ of the suspension was taken at $1,3,7,24$ and $48 \mathrm{~h}$ after the start of the incubation. The taken sample was centrifuged at $1300 \times \mathrm{g}$ for $10 \mathrm{~min}$. The obtained supernatant was analyzed using a BCA Protein Assay kit to determination of the concentration of released LF, which was validated using LF standard samples dissolved in the 1st ( $\mathrm{pH} 1.2)$ and $2 \mathrm{nd}(\mathrm{pH} 6.8)$ fluids.

\section{Enteric coating of LF-loaded Ch microparticles}

The selected LF-loaded Ch microparticles, MS4, were coated with EL-100. MS4 was suspended to the methanol solution containing 200 $\mathrm{mg}$ of EL-100. The suspension was added drop by drop at a fairly rapid speed to $150 \mathrm{~mL}$ of liquid paraffin containing $1 \%(\mathrm{v} / \mathrm{v}) \mathrm{SO}-15$, while the dispersion solvent was being stirred at $600 \mathrm{rpm}$. The resultant emulsion was stirred for $1 \mathrm{~h}$, and sonicated at $28 \mathrm{~Hz}(100 \mathrm{~W})$ for $10 \mathrm{~min}$. The resultant emulsion was evaporated with the reduced pressure at $20^{\circ} \mathrm{C}$ under stirring at $400 \mathrm{rpm}$ until it became to be white suspension. $\mathrm{n}$-Hexane was mixed to the suspension with the same volume, and the mixture was centrifuged at $3000 \times \mathrm{g}$ for $10 \mathrm{~min}$. The precipitate was taken by discarding the supernatant, and washed several times with $\mathrm{n}$-hexane, and dried in a desiccator.

The obtained coated microparticles (E/MS4) were investigated for particle size, shape, drug content and in vitro release in the same manner as stated above.

\section{Results and Discussion}

\section{Preparation and particle characteristics of LF-loaded Ch microparticles}

LF-loaded $\mathrm{Ch}$ microparticles were prepared according to the formulations in Table 1. The microparticles, produced using SO-15 (HLB 4.5 ) and SO-30 (HLB 1.8) as surfactants, were shown in Figures 1 and 2 respectively. The particle size and shape were almost the same in MS1 MS4. On the other hand, the particle size tended to be greater in MT3 and MT4, and their surface was not smooth in comparison with MT1 1nd MT2. In particular, the microparticles with large size had nearly round shape but showed the structure of laminated agglomeration. Table 2 summarizes the particle characteristics. The drug content and encapsulation efficiency were fairly high. The addition of LF at a high ratio tended to exhibit the better encapsulation efficiency.

In the previous paper, chitosan/alginate/Ca (II) complex microparticles loaded with LF was produced [32]. The complex microparticles showed LF content of $15-22 \%(w / w)$. Therefore, MS4 and MT4 exhibited much higher LF content than those complex microparticles. This is an advantage for the present microparticles because a fairly large dose of is needed to get sufficient function of LF.

\begin{tabular}{|c|c|c|c|}
\hline \multirow{2}{*}{$\begin{array}{c}\text { Formulation } \\
\text { code }\end{array}$} & \multicolumn{2}{|c|}{ Formulation composition } & $\begin{array}{c}\text { Surfactant in } \\
\text { dispersion medium }\end{array}$ \\
\cline { 2 - 3 } MS1 & LF (mg) & Ch $\mathbf{( m g )}$ & $1 \%$ SO-15 \\
\hline MS2 & 10 & 50 & $1 \%$ SO-15 \\
\hline MS3 & 20 & 50 & $1 \%$ SO-15 \\
\hline MS4 & 30 & 50 & $1 \%$ SO-15 \\
\hline MT1 & 50 & 50 & $1 \%$ SO-30 \\
\hline MT2 & 10 & 50 & $1 \%$ SO-30 \\
\hline MT3 & 20 & 50 & $1 \%$ SO-30 \\
\hline MT4 & 30 & 50 & $1 \%$ SO-30 \\
\hline
\end{tabular}

Table 1: Formulation composition and used surfactant in the preparation of LFloaded Ch microparticles.

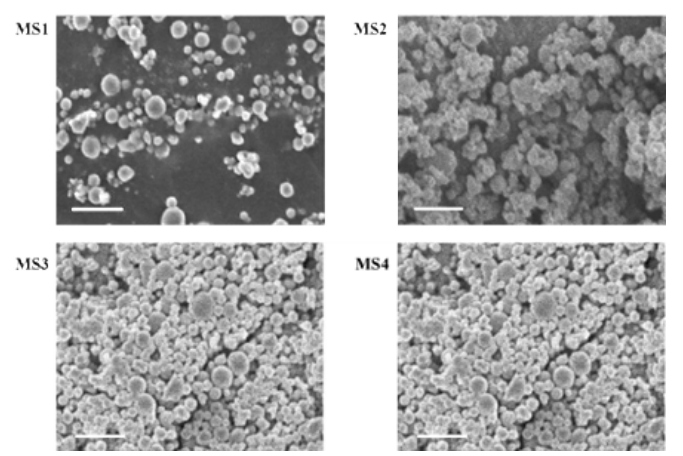

Figure 1: Scanning electron photomicrographs of MS1 - MS4, The bar length $=10 \mu \mathrm{m}$. 

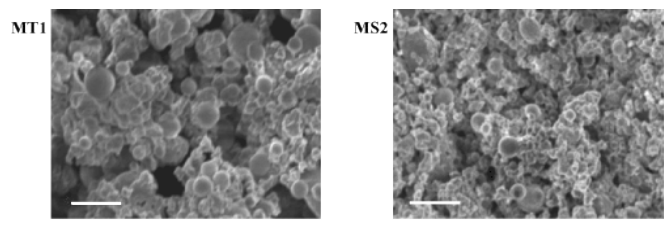

MT
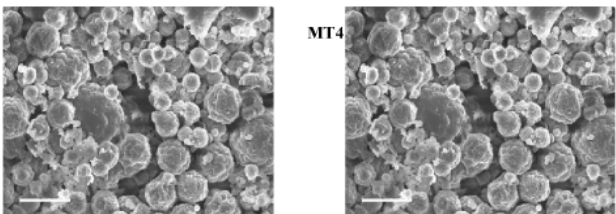

Figure 2: Scanning electron photomicrographs of MT1 - MT4. The bar length $=10 \mu \mathrm{m}$.

\begin{tabular}{|c|c|c|c|}
\hline $\begin{array}{c}\text { Formulation } \\
\text { Code }\end{array}$ & $\begin{array}{c}\text { Particle diameter } \\
(\boldsymbol{\mu m})\end{array}$ & $\begin{array}{c}\text { Drug content } \\
(\mathbf{\%}, \mathbf{w} / \mathbf{w})\end{array}$ & $\begin{array}{c}\text { Encapsulation } \\
\text { Efficiency } \mathbf{( \% )}\end{array}$ \\
\hline MS1 & $1.9 \pm 1.1$ & $11.2 \pm 3.8$ & $67.5 \pm 22.7$ \\
\hline MS2 & $2.0 \pm 0.5$ & $18.9 \pm 3.0$ & $66.2 \pm 10.6$ \\
\hline MS3 & $2.0 \pm 0.9$ & $27.0 \pm 3.7$ & $77.5 \pm 2.2$ \\
\hline MS4 & $1.9 \pm 0.5$ & $38.0 \pm 4.5$ & $75.9 \pm 9.1$ \\
\hline MT1 & $2.7 \pm 1.5$ & $12.5 \pm 1.6$ & $74.8 \pm 9.6$ \\
\hline MT2 & $2.7 \pm 1.0$ & $22.4 \pm 0.7$ & $78.4 \pm 2.4$ \\
\hline MT3 & $3.6 \pm 2.2$ & $27.2 \pm 5.9$ & $72.5 \pm 15.8$ \\
\hline MT4 & $3.4 \pm 2.5$ & $44.2 \pm 2.4$ & $88.4 \pm 4.8$ \\
\hline
\end{tabular}

Table 2: Particle characteristics for LF-loaded Ch microparticles. The results are expressed as the mean \pm S.D. $(n=200$ for particle diameter, $n=3$ for drug content, encapsulation efficiency).

Microparticles, with a size of submicron or near size, appear to show better localization and retention in the intestinal membrane [34,35]. From the viewpoints of the particle size, smooth surface structure and LF content, MS4 was considered to be a best formulation.

\section{In vitro release features of $\mathrm{LF}$-loaded $\mathrm{Ch}$ microparticles}

The release profiles of LF were investigated in the incubation using 1st fluid ( $\mathrm{pH} 1.2)$ and 2 nd fluid $(\mathrm{pH}$ 6.8). The initial rapid release was observed at $\mathrm{pH} 1.2$ for all the MS and MT microparticles, in which the influence of the $\mathrm{LF} / \mathrm{Ch}$ ratio on the release rate was greater in MT microparticles than MS ones. After the initial rapid release, the LF release was very slow. The release profiles were similar among MS1 MS4. The initial rapid release was suppressed at $\mathrm{pH} 6.8$, in which it was less than $40 \%$ for all the MS and MT microparticles. LF was released very slowly after initial release.

MS4, chosen from the particle characteristics, exhibited nearly $80 \%$ release at $\mathrm{pH} 1.2$ in the initial period, and then hardly released LF until $48 \mathrm{~h}$ after the start of the incubation. At pH 6.8, MS4 released LF at approximately $30 \%$ initially, and released LF gradually to approximately $50 \%$ at $48 \mathrm{~h}$ after the start of the incubation.

\section{Enteric coating of LF-loaded Ch microparticles}

Considering these in vitro release features as stated above, it was proposed that the initial release at $\mathrm{pH} 1.2$ had to be suppressed. This was considered to be because the acidic aqueous solution could permeate the $\mathrm{Ch}$ matrix easily. In addition, ss $\mathrm{Ch}$ is subjected to dissolution in the acidic aqueous condition, the micropartiles should be coated with some enteric coating substance to protect their structure.

In this study, MS4, chosen from the above some reasons, was coated using EL-100 by the W/O emulsification-solvent evaporation method.
The coated microparticle SEM photo is shown as Figure 3 (E/MS4, 0 h). The particle diameter was $4.3 \pm 2.4 \mu \mathrm{m}$ (mean \pm S.D., $\mathrm{n}=200$ ), and their surface was smooth; the increase in size was considered to be due to the coating by EL-100. The LF content was more than $22 \%(w / w)$, which suggested that MS4 could be incorporated in E/MS4 at a higher ratio than EL-100. In addition, the in vitro release was estimated to be 9-15\%, 20-39\% and $29-50 \%$ at $1 \mathrm{~h}, 24 \mathrm{~h}$ and $48 \mathrm{~h}$ after the incubation at $\mathrm{pH} 1.2$ at $37^{\circ} \mathrm{C}$. The slightly faster release was observed at $\mathrm{pH} 6.8$. These suggested that E/MS4 could be produced at a fairly high LF content, and that the initial release at $\mathrm{pH} 1.2$ could be suppressed.

MS4 and E/MS4 were examined for the change in particle size and shape in the incubation at $\mathrm{pH}$ 1.2. At the specified time points after the incubation in the 1 st fluid at $37^{\circ} \mathrm{C}$, the microparticles were taken after the centrifugation at $1300 \mathrm{x}$ g for $10 \mathrm{~min}$. Then, the precipitate was washed briefly with water, and dried in a desiccator. The dried sample was observed by SEM as stated above. The resultant SEM micrographs are shown in Figure 4. The particle shape and surface structure of MS4 changed more with time, and particle structure was broken completely. As $\mathrm{Ch}$ is subjected to swelling and dissolution in acidic aqueous solution, MS4 was considered to undergo the deformation or dissolution. On the other hand, the particle size and shape of E/MS4 were scarcely changed even at $24 \mathrm{~h}$ after the start of the incubation, indicating that MS4 could be protected with EL-100 from the deformation at $\mathrm{pH}$ 1.2.

\section{Conclusions}

LF-loaded Ch microparticles were prepared with different formulations. Ch microparticles with high load of LF (approximately $40 \%(\mathrm{w} / \mathrm{w}))$ could be produced at the LF/Ch ratio of $1: 1(\mathrm{w} / \mathrm{w})$ by the
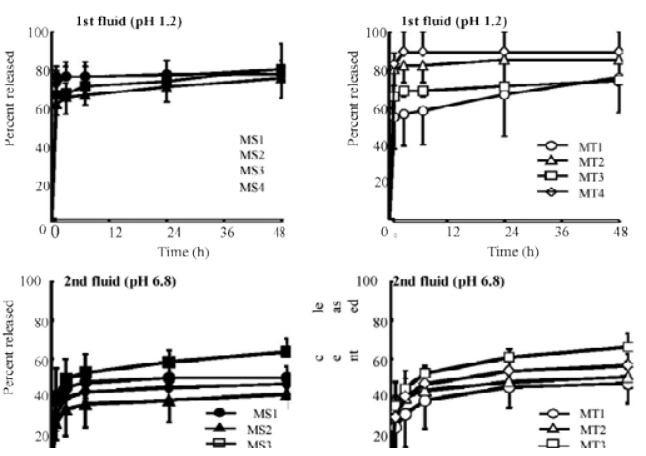

Figure 3: Release profiles of LF from Ch microparticles in 1st and 2nd fluids at $37^{\circ} \mathrm{C}$. Each points represents the mean \pm S.D. $(n=3)$.
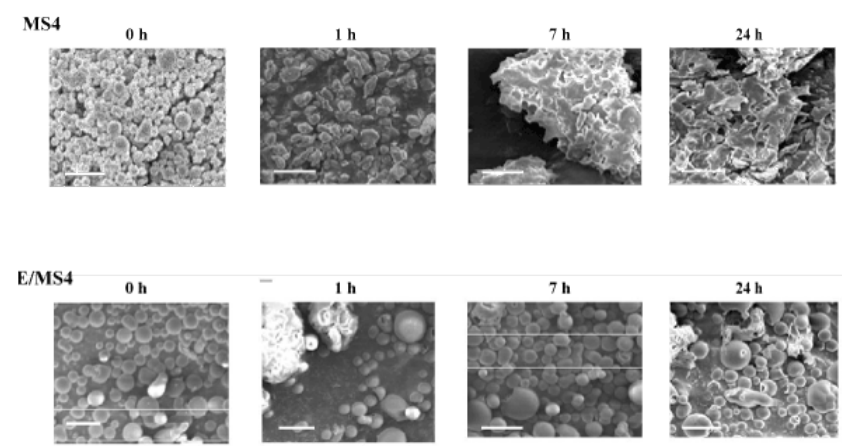

Figure 4: Scanning electron photomicrographs of MS4 and E/MS4 obtained before (0), 1,7 and $24 \mathrm{~h}$ after the incubation in the 1 st fluid at $37^{\circ} \mathrm{C}$. The bar length $=10 \mu \mathrm{m}$. 
O/W emulsification-evaporation method. Furthermore, LF-loaded Ch microparticles, with a size of one ro a few $\mu \mathrm{m}$ and smooth surface, could be obtained using SO-15 as a surfactant. The LF-loaded Ch microparticles with high LF showed similar release profiles among all the formulations; LF was released initially at $\mathrm{pH} 1.2$ at a fairly large extent, and the initial rapid release was suppressed at $30-50 \%$ at $\mathrm{pH} 6.8$. After the initial period, LF was released slowly in both $\mathrm{pH}$ conditions. Based on those particle features and release profiles, the formulation MS4, produced at LF/Ch ratio of $1: 1(\mathrm{w} / \mathrm{w})$ using $1 \%(\mathrm{w} / \mathrm{w}) \mathrm{SO}-15$, was chosen. Furthermore, EL-100 coated MS4 (E/MS4) were found to have fairly high LF content and to show the suppression of the initial release at $\mathrm{pH} 1.2$ and gradual release of LF. Thus, enteric-coated MS4 was suggested to be possibly useful as an oral delivery system of LF.

\section{Author's Contribution}

Hiraku Onishi and Kein-ich Watanbe carried out studies design, experiment and data interpretation. Hiraku onishi also wrote the manuscript. Yoshihary Machida participated in data interpretation.

\section{References}

1. Masson PL, Heremans JF, Schonne E (1969) Lactoferrin, an iron-binding protein in neutrophilic leukocytes. J Exp Med 130: 643-658.

2. Bullen JJ, Rogers HJ, Leigh L (1972) Iron-binding proteins in milk and resistance to Escherichia coli infection in infants. Br Med J 1: 69-75.

3. Weinberg ED (1974) Iron and susceptibility to infectious disease. Science 184: 952-956.

4. Arnold RR, Cole MF, McGhee JR (1977) A bactericidal effect for human lactoferrin. Science 197: 263-265.

5. Jenssen H (2005) Anti-herpes simplex virus activity of lactoferrin/lactoferricin -- an example of antiviral activity of antimicrobial protein/peptide. Cell Mol Life Sci 62: 3002-3013.

6. ligo M, Kuhara T, Ushida Y, Sekine K, Moore MA, et al. (1999) Inhibitory effects of bovine lactoferrin on colon carcinoma 26 lung metastasis in mice. Clin Exp Metastasis 17: 35-40.

7. Togawa J, Nagase H, Tanaka K, Inamori M, Nakajima A, et al. (2002) Ora administration of lactoferrin reduces colitis in rats via modulation of the immune system and correction of cytokine imbalance. J Gastroenterol Hepatol 17: 1291-1298.

8. Legrand D, Elass E, Pierce A, Mazurier J (2004) Lactoferrin and host defence: an overview of its immuno-modulating and anti-inflammatory properties. Biometals 17: 225-229.

9. Orsi N (2004) The antimicrobial activity of lactoferrin: current status and perspectives. Biometals 17: 189-196.

10. Flores-Villaseñor $H$, Canizalez-Román A, Reyes-Lopez $M$, Nazmi $K$, de la Garza M, et al. (2010) Bactericidal effect of bovine lactoferrin, LFcin, LFampin and LFchimera on antibiotic-resistant Staphylococcus aureus and Escherichia coli. Biometals 23: 569-578.

11. Ellison RT 3rd, Giehl TJ, LaForce FM (1988) Damage of the outer membrane of enteric gram-negative bacteria by lactoferrin and transferrin. Infect Immun 56: 2774-2781.

12. Gifford JL, Hunter HN, Vogel HJ (2005) Lactoferricin: a lactoferrin-derived peptide with antimicrobial, antiviral, antitumor and immunological properties. Cell Mol Life Sci 62: 2588-2598.

13. Jenssen $H$ (2005) Anti-herpes simplex virus activity of lactoferrin/lactoferricin -- an example of antiviral activity of antimicrobial protein/peptide. Cell Mol Life Sci 62: 3002-3013

14. Ikeda M, Sugiyama K, Tanaka T, Tanaka K, Sekihara H, et al. (1998) Lactoferrin markedly inhibits hepatitis $\mathrm{C}$ virus infection in cultured human hepatocytes. Biochem Biophys Res Commun 245: 549-553.

15. Jenssen H, Andersen JH, Uhlin-Hansen L, Gutteberg TJ, Rekdal Ø (2004) Anti$\mathrm{HSV}$ activity of lactoferricin analogues is only partly related to their affinity for heparan sulfate. Antiviral Res 61: 101-109.

16. Legrand D, Elass E, Carpentier M, Mazurier J (2006) Interactions of lactoferrin with cells involved in immune function. Biochem Cell Biol 84: 282-290.

17. Onishi H (2011) Lactoferrin delivery systems: approaches for its more effective use. Expert Opin Drug Deliv 8: 1469-1479.

18. Britton JR, Koldovský O (1987) Luminal digestion of lactoferrin in suckling and weanling rats. Am J Physiol 253: G397-403.

19. Troost FJ, Saris WH, Brummer RJ (2002) Orally ingested human lactoferrin is digested and secreted in the upper gastrointestinal tract in vivo in women with ileostomies. J Nutr 132: 2597-2600.

20. Nojima Y, Suzuki Y, Yoshida K, Abe F, Shiga T, et al. (2009) Lactoferrin conjugated with $40-\mathrm{kDa}$ branched poly(ethylene glycol) has an improved circulating half-life. Pharm Res 26: 2125-2132.

21. Talukder MJ, Takeuchi T, Harada E (2003) Characteristics of lactoferrin receptor in bovine intestine: higher binding activity to the epithelium overlying Peyer's patches. J Vet Med A Physiol Pathol Clin Med 50: 123-131.

22. Suzuki YA, Lopez V, Lönnerdal B (2005) Mammalian lactoferrin receptors: structure and function. Cell Mol Life Sci 62: 2560-2575.

23. Shimizu H1 (2004) Development of an enteric-coated lactoferrin tablet and its application. Biometals 17: 343-347

24. Nojima Y, Suzuki Y, Iguchi K, Shiga T, Iwata A, et al. (2008) Development of poly(ethylene glycol) conjugated lactoferrin for oral administration. Bioconjug Chem 19: 2253-2259.

25. Takeuchi T, Kitagawa $\mathrm{H}$, Harada $\mathrm{E}$ (2004) Evidence of lactoferrin transportation into blood circulation from intestine via lymphatic pathway in adult rats. Exp Physiol 89: 263-270.

26. Drescher K, Roos N, Pfeuffer M, Seyfert HM, Schrezenmeir J, et al. (1999) Recovery of $15 \mathrm{~N}$-lactoferrin is higher than that of $15 \mathrm{~N}$-casein in the small intestine of suckling, but not adult miniature pigs. J Nutr 129: 1026-1030.

27. Takeuchi T, Jyonotsuka T, Kamemori N, Kawano G, Shimizu H, et al. (2006) Enteric-formulated lactoferrin was more effectively transported into blood circulation from gastrointestinal tract in adult rats. Exp Physiol 91: 1033-1040.

28. Synowiecki J, Al-Khateeb NA (2003) Production, properties, and some new applications of chitin and its derivatives. Crit Rev Food Sci Nutr 43: 145-171.

29. Hejazi R, Amiji M (2003) Chitosan-based gastrointestinal delivery systems. J Control Release 89: 151-165.

30. Yoshino T, Machida Y, Onishi H, Nagai T (2003) Preparation and characterization of chitosan microspheres containing doxifluridine. Drug Dev Ind Pharm 29: 417-427.

31. Onishi H, Oosegi T, Machida Y, McGinity JW (2005) Preparation and in vitro evaluation of chitosan microspheres containing prednisolone: comparison of simple and conjugate microspheres. Drug Dev Ind Pharm 31: 597-605.

32. Onishi H, Machida Y, Koyama K (2007) Preparation and in vitro characteristic of lactoferrin-loaded chitosan microparticles. Drug Dev Ind Pharm 33: 641-647.

33. Onishi H, Koyama K, Sakata O, Machida Y (2010) Preparation of chitosan alginate/calcium complex microparticles loaded with lactoferrin and their efficacy on carrageenan-induced edema in rats. Drug Dev Ind Pharm 36: 879884

34. Kawashima Y, Yamamoto H, Takeuchi H, Kuno Y (2000) Mucoadhesive DLlactide/glycolide copolymer nanospheres coated with chitosan to improve oral delivery of elcatonin. Pharm Dev Technol 5: 77-85.

35. Lamprecht A, Schäfer U, Lehr CM (2001) Size-dependent bioadhesion of micro- and nanoparticulate carriers to the inflamed colonic mucosa. Pharm Res 18: $788-793$ 